\title{
Novel bird responses to successive, large-scale, landscape transformations
}

\author{
David B. Lindenmayer, ${ }^{1,2,3}$ Wade Blanchard, ${ }^{1}$ Martin J. Westgate, ${ }^{1,2}$ Claire Foster, ${ }^{1}$ Sam C. Banks, ${ }^{1}$ \\ Philip Barton, ${ }^{1}$ Mason Crane, ${ }^{1,2}$ Karen Ikin, $^{1}$ and Ben C. Scheele ${ }^{1}$ \\ ${ }^{1}$ Fenner School of Environment and Society, The Australian National University, Acton, Australian Capital Territory 2601 Australia \\ ${ }^{2}$ Sustainable Farms, Fenner School of Environment and Society, The Australian National University, Acton, Australian Capital \\ Territory 2601 Australia
}

Citation: Lindenmayer, D. B., W. Blanchard, M. J. Westgate, C. Foster, S. C. Banks, P. Barton, M. Crane, K. Ikin, and B. C. Scheele. 2019. Novel bird responses to successive, large-scale, landscape transformations. Ecological Monographs 00(00):e01362. 10.1002/ecm.1362

\begin{abstract}
Transformation of intact vegetation into new kinds and configurations of human-modified habitats is a well-established driver of biodiversity loss. Following initial conversion, many human-dominated landscapes are then subject to further large-scale changes in land use. The impacts on biodiversity of repeated changes in land use remain poorly known, particularly how changes in the matrix interact with initial patterns of vegetation clearing. We used an 18-yr study of birds in remnant patches of endangered temperate woodland in southeastern Australia to quantify the spatial and temporal effects of successive land use transformation in the surrounding landscape. We examined bird response to (1) initial patterns of landscape modification (creating semi-cleared grazing land dominated by pastures that surrounded remnant woodland patches), (2) subsequent establishment and maturation of exotic tree plantations on the pastures surrounding woodland patches, and (3) additive and interactive effects of both types of landscape transformation. The majority of the 57 bird species modeled responded to conversion of grazing land to exotic plantations, either independently from initial patterns of landscape transformation (20 species), or interactively (18 species) or additively (15 species) with initial landscape transformation. The occurrence of only one species (the Common Bronzewing) was related to patterns of initial transformation but not subsequent transformation due to plantation establishment. Thus, despite many characteristics of the woodland patches within the plantation remaining largely unaltered throughout our 18-yr investigation, the matrix had a profound effect on the kinds of species inhabiting them, with such impacts often magnified over time as the matrix continued to change. Plantation establishment triggered new regional-level spatial processes with effects on birds detected in woodland patches up to $2 \mathrm{~km}$ away from the plantation. Matrix conversion selected for species with different traits (size, diet and movement patterns) compared to the initial transformation, suggesting it is acting as a different filter on the bird community. New kinds of landscape transformation (such as plantation establishment on previously cleared land) can radically affect the species that have persisted for many decades in previously modified landscapes. This highlights the challenges, but also opportunities, for conserving taxa in ever changing human-dominated environments.
\end{abstract}

Key words: habitat fragmentation; interacting land use effects; landscape change; life history attributes; long-term study; temperate woodland; the matrix; traits; tree plantation expansion; woodland birds.

\section{INTRODUCTION}

The conversion of formerly intact native ecosystems to new kinds of human-dominated landscapes, such as those used for cropping, livestock grazing or tree plantations is widespread globally (Venter et al. 2016), and its negative effects on biodiversity are well documented

Manuscript received 19 April 2018; revised 7 November 2018; accepted 20 December 2018. Corresponding Editor: John Marzluff.

${ }^{3}$ E-mail: david.lindenmayer@anu.edu.au
(Lindenmayer and Fischer 2006, Haddad et al. 2015, Barlow et al. 2016, Maxwell et al. 2016). However, following initial transformation, patterns of vegetation cover and structure rarely remain static in human-dominated landscapes, but rather are repeatedly altered through changes in human land use (Felton et al. 2010, Watson et al. 2014). Indeed, successive large-scale changes in human land use are increasingly common worldwide (Watson et al. 2014, Hua et al. 2016). An example of successive transformation is the clearing of intact forest to create semi-cleared grazing land (Galetti et al. 2013) followed by plantation establishment on 
those pastures (Bauhus et al. 2010, Felton et al. 2010, Lindenmayer et al. 2015, Hua et al. 2016). Another example is the establishment of oil palm plantations on land that formerly supported rubber and other crops and, prior to that, rainforest (Basiron 2007). These transformations encompass a conversion to a new, human-dominated land use, making them different from natural ecosystem regeneration after disturbances such as wildfire, which usually entail the recovery of the original ecosystem (Lindenmayer and Franklin 2002, Frelich 2005).

Some well-studied areas of ecological research are relevant to investigations of landscape transformations. Biological legacy theory (sensu Franklin and MacMahon 2000) is a key example. Successive changes in land use often leave biotic and abiotic legacies (Franklin and MacMahon 2000) of the previous form(s) of land cover such as patches of native vegetation, large old trees, rocky outcrops, and lakes and pools. How species respond to these biological legacies following successive changes in the kinds of land use in the landscape that surrounds them (the matrix, sensu Driscoll et al. 2013) is not well understood. Indeed, matrix conversion (sensu Forman 1995) is likely to have a range of effects on species dependent on biological legacies (such as habitat-patch-dependent taxa) such as through influencing movement, altering resources, and modifying the abiotic environment (reviewed by Driscoll et al. 2013).

Most investigations on the effects of the matrix on biodiversity are snapshot or cross-sectional studies (sensu Cunningham and Lindenmayer 2016) that compare biodiversity in native vegetation patches surrounded by different kinds of matrix at a single point in time (Ricketts 2001, Lindenmayer and Fischer 2006). However, the assumption that comparing different matrices at the same time can accurately predict the effects of the temporal process of matrix conversion is problematic in space-for-time substitution studies (Likens 1989). In an important conceptual article, Watson et al. (2014) argued that the history of matrix conversion (the type, the order, and duration of successive transformations) can lead to markedly different effects on biodiversity. That is, it is not just the current matrix conditions surrounding a patch but also the history of land use change that affects biota in that patch. Thus, for example, landscapes subject to successive transformations from intact forest to a semi-cleared grazing system to a tree plantation might support quite different assemblages of species relative to ones where an intact forest is converted directly to a plantation. However, there is currently limited empirical evidence regarding the extent to which effects of the most recent transformation may be influenced by the legacy effects of a preceding transformation (although see Law et al. 2014, 2017, Yanjiao et al. 2017), including in additive or interactive ways (Fig. 1). For example, reforestation of a cleared agricultural matrix could improve the status of dispersal-limited species persisting in fragmented remnant habitats. However, such improvements are dependent on remnant habitat patches supporting populations of sufficient size and genetic diversity to facilitate recovery (i.e., related to patterns of initial landscape conversion such as patch size), and on the ability of dispersal-limited species to move through the new matrix (which also may vary through time; Driscoll et al. 2013).

Improved understanding of the effects of repeated landscape transformation is crucial to determine whether new kinds of landscape transformation will exacerbate or mitigate the impacts of preceding transformation(s). By altering attributes such as landscape connectivity and abiotic conditions, subsequent transformations may create new filters on biodiversity. The state of biodiversity following multiple matrix conversions will depend on the strength of these filters and how they interact. It is therefore necessary to evaluate whether existing research that compares the effects of different matrix types on biodiversity can adequately predict the effects of repeated conversion of the matrix on biodiversity in human dominated landscapes. We argue there is an urgent need for improved understanding of repeated transformations not only because of the increasing prevalence of human-modified landscapes undergoing large-scale land use change, but also because modification of already altered landscapes is rarely subject to the same regulatory controls as the clearing of intact habitat (Giam et al. 2011), despite the importance of highly modified landscapes for the persistence of many species (Range et al. 2015).

Here, we report the results of an 18-yr, 30,000-ha landscape ecology experiment in southeastern Australia. We tested the response of bird biota to the legacy of initial landscape transformation, which entailed clearing of native temperate woodland to create a matrix of cleared paddocks for livestock grazing surrounding remnant woodland patches, the impacts of subsequent conversion of the matrix from semi-cleared farmland to exotic tree plantations, and the spatial and temporal interaction of these two successive transformations. Our study design included (1) a set of 56 woodland remnant patches of varying size and connectedness, surrounded by semicleared farmland that was then converted to exotic Radiate Pine plantations, (2) a matched set of 55 woodland patches surrounded by semi-cleared farmland that was not converted to stands of exotic pine but was located adjacent (200-6,000 m) to the plantation, and (3) a reference set of 29 woodland patches surrounded by farmland and located $>30 \mathrm{~km}$ away from any plantation establishment (see Methods). A key strength of this investigation was therefore that it was underpinned by a large number of woodland patches with a shared history of initial conversion. We then quantified the longitudinal effects of a subsequent transformation to an exotic plantation surrounding a subset of these patches, while the 

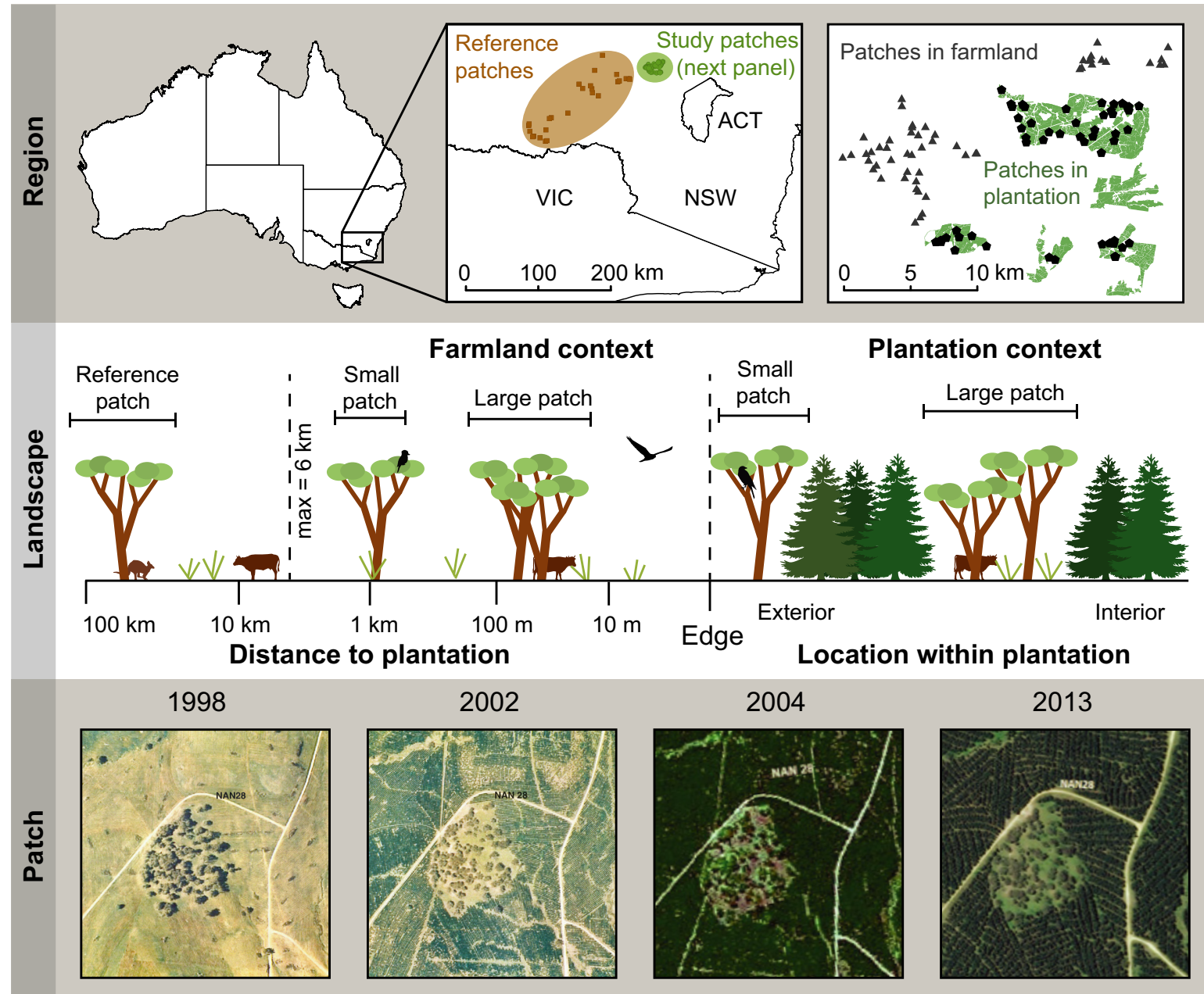

FIG. 1. Location of the study region in southeastern Australia (top row) showing a conceptual diagram of the design for our large-scale study of landscape transformation associated with exotic plantation establishment (middle row). Time series photographs (bottom row) show changes in landscape cover around one of the 111 box-gum grassy woodland patches (patch Nan28), which drove an array of time-varying main and interaction effects of landscape transformation on bird biota (Photos by NSW Forestry Corporation).

matrix surrounding the remaining patches remained unchanged (Fig. 1).

Specifically, we empirically tested five competing hypotheses about how biodiversity responds to successive landscape transformations:

Hypothesis 1. There are no effects of either the preceding, nor the subsequent, landscape transformation. This is a null model and bird occurrence in woodland patches may vary over time or between regions but not in response to landscape transformation.

Hypothesis 2. Legacy effects of the initial transformation associated with clearing of original native vegetation are dominant. This hypothesis assumes that much of the disturbance-sensitive biota were lost as a result of the initial transformation (clearing of temperate woodland to create pastures for livestock grazing), and therefore that subsequent transformation will have limited effects on the suite of species that persist in such environments. That is, bird occurrence will be related only to attributes of remnant patches of original vegetation cover (e.g., patch size and connectivity) remaining after initial transformation.

Hypothesis 3. Effects of new plantation-generated transformation are dominant. The occurrence of species is not related to patterns of initial transformation but strongly influenced by attributes associated with subsequent transformation (in which plantations were established on previously cleared land; e.g., type of transformation, time since transformation, or spatial proximity to the transformed landscape). Therefore, transformation of the matrix 
around patches of original vegetation cover will have substantial effects on resident species.

Hypothesis 4. Initial and subsequent transformations have combined effects. Under this hypothesis, the most recent (plantation-generated) transformation has effects in addition to, and independent of, the effects of initial transformation (additive effects). For example, a small shrubnesting species might be more common in large patches, and in patches surrounded by plantation, but the plantation does not affect its occurrence in small vs. large patches. Alternatively, the effects of the most recent (plantation-generated) transformation may be mediated by the legacy of initial transformation (interactive effects). For example, a species that can disperse easily through farmland, but not through dense plantations, may be unaffected by plantation establishment encompassing well-connected patches, but may be lost from isolated patches following plantation establishment.

Hypothesis 5. Initial and subsequent transformation select for different bird life history traits. Under this hypothesis, changes in landscape structure associated with plantation-generated transformation select for different traits than those selected for by the initial process of converting formerly widespread temperate woodland to cleared pastures for livestock grazing. This is the "performance filtering hypothesis" (Mouillot et al. 2012, Barnagaud et al. 2014) and given that the matrix surrounding woodland patches might be expected to affect movement and alter resources (Driscoll et al. 2013), these influences would be manifested through different filters on the broad functional kinds of species likely to be benefit or be disadvantaged by conversion of the matrix surrounding woodland patches.

\section{Methods}

\section{Study area and study design}

We quantified the response of birds in remnant patches of endangered box-gum grassy woodland in three broad categories of sites. These were as follows: (1) woodland patches surrounded by cleared pastures in a farming landscape with those pastures then planted to stands of exotic radiata pine (Pinus radiata), (2) woodland patches surrounded by cleared pastures in a farming landscape and located from $200 \mathrm{~m}$ up to $6,000 \mathrm{~m}$ from where the plantation was established, and (3) woodland patches surrounded by cleared pastures and located a farming landscape located $>30 \mathrm{~km}$ away from any plantation establishment (termed "reference farmland patches").
The dominant species of trees in our woodland patches were yellow box (Eucalyptus melliodora), white box (E. albens), red box (E. polyanthamos), Blakely's red gum (E. blakelyi), and red stringybark (E. macrorhyncha). Prior to European settlement, our study region supported extensive areas of these temperate woodlands. The region was semi-cleared for livestock grazing during the $1880 \mathrm{~s}$, and then experienced intensified clearing to establish grazing pastures in the 1950s (Lindenmayer et al. 2016b). Clearing has removed $95-99 \%$ of the original native vegetation cover and large areas of intact temperate woodland vegetation (e.g., those exceeding $100+$ ha) do not exist (Gibbons and Boak 2002, Lindenmayer et al. 2010). Hence, we were unable to include a potential example of the bird biota in uncleared habitats because of the paucity of extensive areas of temperate woodland vegetation.

We established our study in 1998 when a 15,000-ha semi-cleared farming area was being targeted for transformation to a radiata pine plantation. We employed a randomized and replicated patch selection procedure to identify 56 remnant woodland patches within the to-beestablished plantation ("plantation patches"; see Lindenmayer et al. 2008, Lindenmayer 2009; Fig. 1). The plantations in our study areas were established over a six-year period between 1995 and 2000. Our field surveys were conducted in 1998, 1999, 2000, 2001, 2003, 2005, 2007, 2009, 2011, 2012, 2013, 2014, and 2015. Hence, we have observations of birds for every year of plantation age (i.e., time since plantation establishment) from 0 to $18 \mathrm{yr}$.

During the time we established sites within the woodland patches in the plantation, we also selected a set of 55 woodland patches that remained surrounded by cropping and grazing pastures ("farmland patches"), and that were located at distances of $200-6,000 \mathrm{~m}$ from the plantation (Lindenmayer et al. 2001). We matched the 55 woodland remnants with the 56 woodland remnants located within the plantation on the basis of size, woodland vegetation type, climatic conditions, and other factors (Lindenmayer et al. 2001).

Our study design encompassed woodland patches varying in size (0.4-28.9 ha; larger patches do not exist because of the extent of past land clearing), connectivity (percent native vegetation cover in the surrounding $1,000 \mathrm{~m}$ ), landscape context (four levels; farmland [woodland patch surrounded by cropping and grazing pastures, nearby to the plantation], plantation interior [woodland patch completely surrounded by plantation], plantation edge [woodland patch is within plantation but with one or two sides exposed to farmland], and distant "reference" farmland [see Farmland reference sites]), and, for farmland patches, distance to plantation. Importantly, all woodland patches within the plantation and within the farmland were subject to grazing by domestic livestock (primarily sheep [Ovis aries] and cattle [Bos taurus]), except for the first two years when plantation seedlings were being established to avoid damage 
to young trees. We therefore were able to avoid confounding between landscape transformation and grazing regimes.

\section{Farmland reference sites}

In addition to surveys at our 111 plantation and farmland patches, we conducted bird surveys between 2002 and 2015 at a further 29 farmland reference patches surrounded by cleared grazing and cropping land and located $>30 \mathrm{~km}$ away from the quasi-experiment. We ensured that the reference sites were in the same broad bioregion as the woodland remnants in the plantation and the neighboring farmland and were characterized by similar climatic conditions and woodland vegetation types. The pastures surrounding these external reference patches were not subject to plantation establishment and their inclusion enabled us to determine whether temporal changes observed for birds could be attributed to plantation-derived landscape transformation or were indicative of broader regional trends. For the purposes of this study, we assumed that a distance of $30 \mathrm{~km}$ from the plantation was sufficient for there to be no plantation adjacency effects.

We selected the 29 external reference patches from a large, long-term study conducted across 203 woodland patches that is investigating bird responses to vegetation cover in southeastern Australia (Cunningham et al. 2014, Lindenmayer et al. 2016a). We selected the 29 patches based on matching vegetation type, patch size and broad structural similarity (viz old growth woodland) to woodland patches in the quasi-experiment. In addition, the hyper-aggressive native honeyeater, the Noisy Miner (Manorina melanocephala), was rare or absent at selected external reference patches - consistent with its absence or low abundance in our 111 experimental woodland patches.

\section{Other areas targeted for survey}

In addition to the 111 woodland patches in the quasiexperiment, and the 29 external reference patches, we also established 10 sites in pastures surrounding the woodland patches and a further 10 sites dominated by stands of radiata pine that surrounded the woodland patches in the plantation. These sites represent the matrix (sensu Driscoll et al. 2013) in the area subject to plantation-generated transformation and the matrix in areas subject to initial landscape transformation to semicleared farmland. We have surveyed these 20 sites repeatedly since 1998 (at the same time as other surveys). However, we do not present data from them because the avifauna they support is a small subset of (and does not add any new species to) the species pool across our study region. Moreover, the vast majority of small number of individual species inhabiting matrix sites such as those dominated by stands of radiata pine, were rare and hence we elected to exclude data gathered from these sites from the analyses we present here.

\section{Field survey protocols}

Our bird survey protocols, transect design and establishment, and set of observers collecting field data were the same for the quasi-experimental patches and for the external reference patches. In each patch, we established a $200 \mathrm{~m}$ long transect with permanent markers at the 0 $\mathrm{m}, 100-\mathrm{m}$, and $200-\mathrm{m}$ points along the transect, except for patches measuring $0.4-1$ ha in size where a $100-\mathrm{m}$ transect was established. We counted birds at the 0-, 100-, and 200-m stations along each transect using 5min point counts. We conducted surveys in spring in any given year as this is the period when species are most active and calling most frequently. We completed surveys between 05:30 and 10:00 in the morning but abandoned them on days of poor weather and high wind. In each survey year, we surveyed all patches twice on a different day by a different observer. Only expert ornithologists with more than 10 years of field experience participated in field surveys, with typically six observers completing surveys in any given year. We employed these protocols to reduce day effects and observer heterogeneity (Lindenmayer et al. 2008, 2016a). We recorded only those birds seen or heard within $50 \mathrm{~m}$ of the sample point to ensure that counts corresponded to the particular patch being surveyed. Thus, in any given year, we completed a minimum of six point counts or 30 minutes of field surveys at site. We did not treat point counts at a given station on a given transect as independent. Rather, we pooled data for the two surveys on the two different days and calculated the presence/absence of each species.

\section{Data analysis}

Despite extensive human modification, our study region is biodiverse and, over the $18 \mathrm{yr}$ of bird surveys, we recorded 130 bird species, including more than 20 species of conservation concern (Lindenmayer 2009, Lindenmayer et al. 2016b). For our analysis, we focused on the 57 species for which we recorded 100 or more occurrences (Appendix S1) and for which there were sufficient data to construct robust statistical models.

The first part of our analysis addressed which of the first four hypotheses outlined in Introduction best described the observed presence/absence pattern of the 57 bird species under study. We constructed 30 models for each species from the following explanatory variables: (1) landscape context (remnant woodland patches): (a) located on the interior of the plantation (surrounded by pine), (b) located on the exterior of the plantation (had at least one patch edge adjacent to open farmland), (c) located within farmland adjacent to the plantation, or (d) located within farmland distant from the plantation (reference farmland patches); (2) logarithm of patch size; (3) connectivity (the amount of 
native vegetation in the surrounding $1,000 \mathrm{~m}$ radius area); and (4) the distance to the plantation (for farmland patches only). A complete list of models and which of the four hypotheses to which they correspond is given in Appendix S2: Table S1.

We did not adjust for detection for our bird data in this study given that there are significant issues outlined with its application (Hutto 2016), including our study system, where it does not improve model fit (see Welsh et al. 2013, 2015). Further, detectability analysis had not been developed when this study commenced in 1998 and to ensure consistency across all years of survey, our field methods have remained unchanged. In addition, because sampling effort was constant and surveys were completed largely by the same set of highly experienced observers, we expected detectability to be similar among patches. The structure and tree and shrub density of the woodland patches have not changed substantially over time, and given that most records were by hearing (and not visual sighting), we assumed that detection/occupancy analysis would have led to limited if any change to the results, even if it could have been validly applied in this context (see Welsh et al. 2013, 2015). Finally, our experimental design and standardized survey methods meant that even in dry years, the differences among sites within a year would be maintained.

We used generalized linear mixed models for individual species presence/absences (modeled with a Bernoulli distribution and a logit link). All models included a random effect for site to account for unexplained temporal dependence and included a spatial auto-covariate that was computed for each year of observation. In addition, when time since plantation establishment was included in the model, we allowed the slope of time since plantation establishment to vary by site. We compared models using the WAIC (widely applicable information criterion; Watanabe 2010, Gelman et al. 2014, Vehtari et al. 2015), and selected the model with the smallest number of parameters from among all models within two WAIC units of the best fitting model. We employed a Bayesian approach and assigned independent Cauchy distributions (location $=0$, scale $=2.5$ ) to all regression parameters and a half-Cauchy distribution (location $=0$, scale $=10)$ to the random effect standard deviations (Gelman et al. 2008). We elected to use Cauchy priors rather than uninformative priors to improve the efficiency of the Markov chain Monte Carlo (MCMC) algorithm and, more importantly, to deal with potential complete/partial separation. The Cauchy prior has much shorter tails compared to an uninformative prior, and hence does not allow the parameter estimates to approach infinity when complete/partial separation is present. We also standardized the continuous variables in our models to have zero mean and standard deviation of one half (Gelman et al. 2008) to improve the efficiency of the MCMC algorithm. We report estimates and credible intervals on the standardized covariate scale; however, we present graphics on the original predictor scale. We conducted our analysis using the brms package (Buerkner 2017) in $\mathrm{R}$ version 3.2.1 (R Core Team 2015) using the RStudio (RStudio Team 2015) interface. We provide additional model details in Appendix S2: Tables S1 and S2.

For the second stage of our analysis, we used the following bird life history traits: movements, main food, main nest site, and cube root of body mass (Appendix S1) to investigate whether traits mediated the effects of initial landscape transformation to create cleared pastures around woodland patches and subsequent plantation-generated landscape transformation. We implemented a parametric approach to the fourth corner problem using the previously mentioned traits in the R package Boral (Hui 2016). We fit the model with a common set of covariates: the additive effect of both kinds of landscape transformation. Our primary focus was on the interaction of the traits and the initial and plantation-generated landscape transformation variables (Model 9 of Appendix S2: Table S1). The univariate approach described previously allows for the inclusion of the spatial auto-covariate and the random intercepts and slopes for the time since plantation establishment effects, which are not currently implemented in the Boral package. We note the Boral package uses a probit link function for binary data.

\section{RESULTS}

We found that plantation-generated transformation variables (time since plantation establishment, and proximity to the plantation) were important for 53 of 57 modeled bird species (Appendix S2: Tables S1 and S2; Appendix S3), including five species of conservation concern. Only one species responded solely to variables associated with the initial transformation (patch size and connectivity); but not subsequent transformation associated with plantation establishment (Appendix S2: Tables S1 and S2; Appendix S3). Four of the 57 species responded to neither form of transformation.

Of the 57 species we modeled, 20 responded only to plantation-generated transformation variables with no effect of initial transformation variables (Appendix S2: Table S1). The legacy of initial transformation continued to be influential during the process of subsequent plantation-generated transformation effects for 33 species. Of these, 15 species responded to the additive effects of both kinds of transformation variables, whereas 18 species responded to the interaction between both kinds of transformation variables, (Appendix S1: Table S1). As an example of interactive effects, within woodland patches fully surrounded by the plantation, nine species increased and 23 species decreased in occurrence, as the plantation matured (Fig. 2; Appendix S3).

We ranked bird species responses to patch condition following initial habitat transformation (i.e., patch size and connectivity), to the establishment of the plantation, and to their interaction from simple to complex 

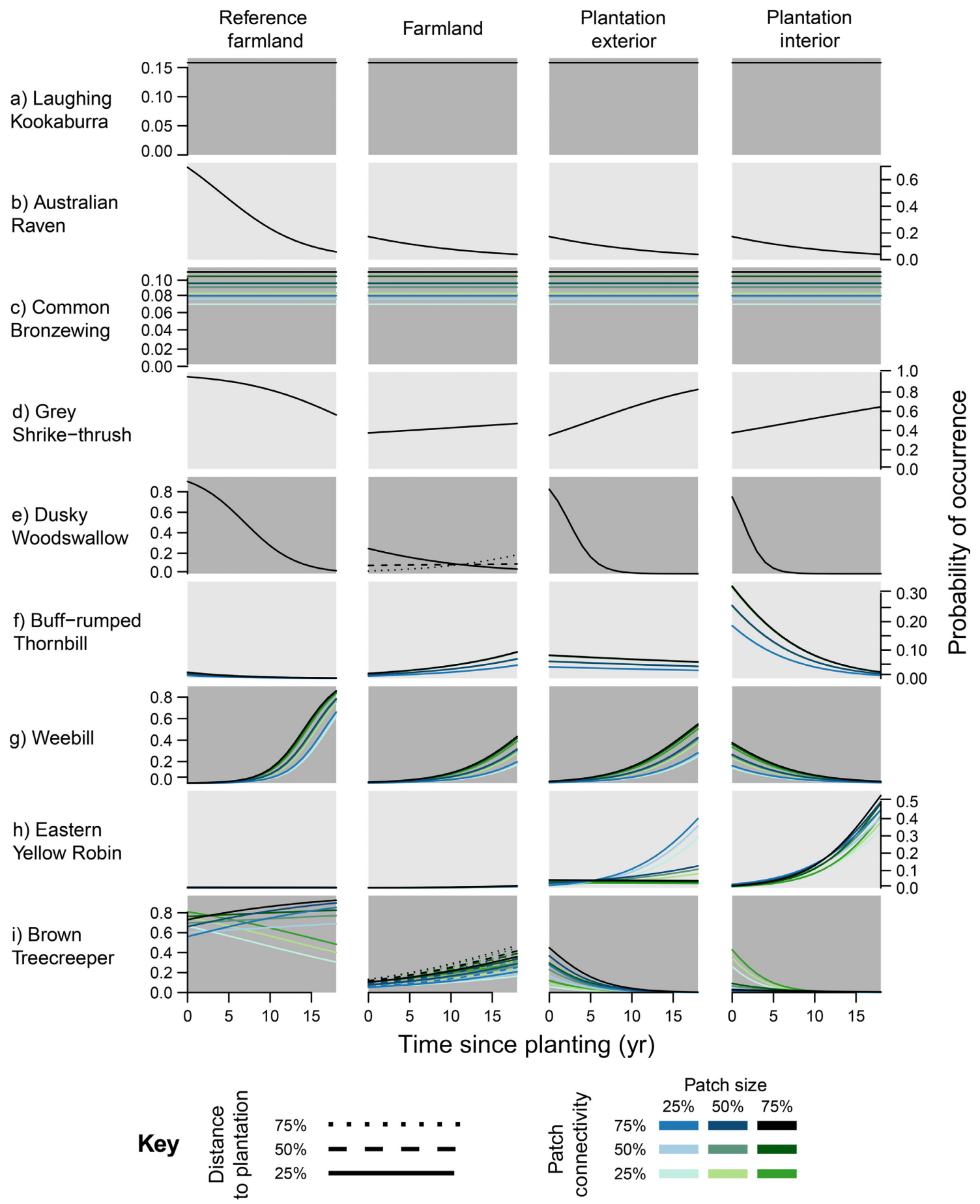

FIG. 2. Individual bird species occurrence ( $y$-axis) with increasing time since plantation establishment ( $x$-axis) and patch context (columns) for nine selected species (rows). Multiple lines within each panel show variability in predictions resulting from other variables in each model. Species are arranged from top to bottom in order of increasing complexity of the selected model (see Appendix S3 for corresponding plots for all bird species).

(Fig. 2 presents responses of nine example species, see Appendix S3 for all species). The responses of species we documented included those of a range of taxa of conservation concern (as defined by Montague-Drake et al. 2009). Only three species we modeled showed no effect of any of our predictor variables, including the Laughing Kookaburra (Fig. 2a) and Pied Currawong (Appendix S3: Fig. S1). A second subset of species 
showed differences in occurrence between contexts but not changes in trajectory (e.g., Australian Raven, which declined in across all areas; Fig. 2b); responses to patch condition but not context (e.g., Common Bronzewing, Fig. 2c); or different trajectories in occurrence between landscape contexts such as the Grey Shrike-Thrush (Fig. 2d), Common Blackbird, Galah, Red-rumped Parrot, and Silvereye (Appendix S3: Fig. S1). As examples, the Buff-rumped Thornbill (Fig. 2f) and the Dusky Woodswallow (see Fig. 2e and which is species of conservation concern) both declined in all landscape contexts except for farms adjacent to the plantation. A final group of species showed complex responses to the full suite of variables included in our analysis (Fig. 2g-i, Weebill, Eastern Yellow Robin, and Brown Treecreeper) as well as the Jacky Winter and Gang-gang Cockatoo [Appendix S3: Fig. S1]). For example, the Weebill became increasingly common in all patch contexts except plantation interior patches, and these increases were greatest in larger, more wellconnected, patches (Fig. 2g). The Eastern Yellow Robin was virtually absent from the reference and farmland sites but increased in woodland patches in the plantation, particularly those in the plantation interior, even when such patches were relatively small and poorly connected (Fig. 2h; Appendix S3, Fig. S1). By contrast, another species of conservation concern, the Brown Treecreeper declined over time in both exterior and interior plantation patches but increased in farmland patches, except for reference farmland patches with low connectivity where this species declined markedly (Fig. 2i). The Rufous Whistler (also a species of conservation concern) increased substantially in reference patches but remained unchanged over time in farmland adjacent to the plantation. In addition, the species increased in occurrence in small and medium sized woodland patches within the plantation but declined in medium and large-sized woodland patches in the interior of the plantation (Appendix Table S3: Fig. S1).

We found that, in patches that remained surrounded by farmland, bird population trajectories were often markedly different from those within woodland patches located in the plantation (Fig. 2; Appendices S2, S3). The Crested Shrike-tit (a species of conservation concern) declined in all landscape contexts, with the most pronounced reductions occurring in woodland patches in both the exterior and interior of the plantation where it had become locally extinct by the end of our study (see Appendix S3: Fig. S1). Furthermore, several species that persisted in woodland patches within the plantation boundary displayed marked differences in occurrence depending on whether a patch was adjacent to the plantation boundary with agricultural land rather than being surrounded on all sides by pine plantations (e.g., Brown Treecreeper, Fig. 2h). Notably, bird responses to plantation establishment sometimes extended up to $2 \mathrm{~km}$ beyond the plantation boundary.
One species was more likely to occur in woodland patches close to the plantation (e.g., Yellow-faced Honeyeater; Appendix S3: Fig. S1) and five in patches distant from the plantation (e.g., Fig. 2e, Dusky Woodswallow and White-throated Gerygone [see Appendix S3: Fig. S1]). In addition, as the plantation matured, one species increased in occurrence in farmland woodland patches distant from the plantation and two species increased in occurrence in farmland woodland patches close to the plantation (Appendix S2: Table S1).

\section{Life history traits analysis}

Using multivariate latent variable models, we found evidence of differences in life history responses to patterns of initial transformation vs. subsequent plantationgenerated transformation (Fig. 3; Appendix S4). Species movement, main diet, and nesting preferences were all associated with bird responses to initial transformation variables: both migratory and insectivorous species were more likely to be recorded in larger patches and in better connected patches; birds that nested in tree cavities or burrows or used horizontal forks or branches were more likely to occur in larger patches and more connected patches compared to birds employing other nesting strategies (Fig. 3; Appendix S4).

We found that bird movements, diet, and body size were associated with responses to plantation-generated transformation. Larger birds declined with time since plantation establishment at a faster rate than small birds, except in woodland patches completely surrounded by plantation (Fig. 3a). The effect of time since plantation establishment was significantly stronger for insectivores in woodland patches within farmland, both adjacent to the plantation as well as in distant reference woodland patches (Fig. 3b). A strong effect also was evident for resident species when compared with migratory species in woodland patches on farmland (Fig. 3c). Finally, species nesting on horizontal forks became more prevalent further away from the plantation as it matured, in contrast to birds that nested in shrubs and understory and those that employed various nesting strategies that became more prevalent closer to the plantation as it matured.

\section{Species richness response}

Given the prevalence of plantation-generated transformation effects on individual species (Fig. 2; Appendix S2: Tables S1 and S2 and Appendix S3), we found that it had a surprisingly limited effect on overall species richness. Species richness declined slightly in woodland patches around which plantation establishment occurred (an average of 0.7 species lost per site over $\sim 18 \mathrm{yr}$ ). In contrast, species richness increased in woodland patches located within farmland adjacent to the plantation, by an average of two species per site over 
a) Body mass (cube root)

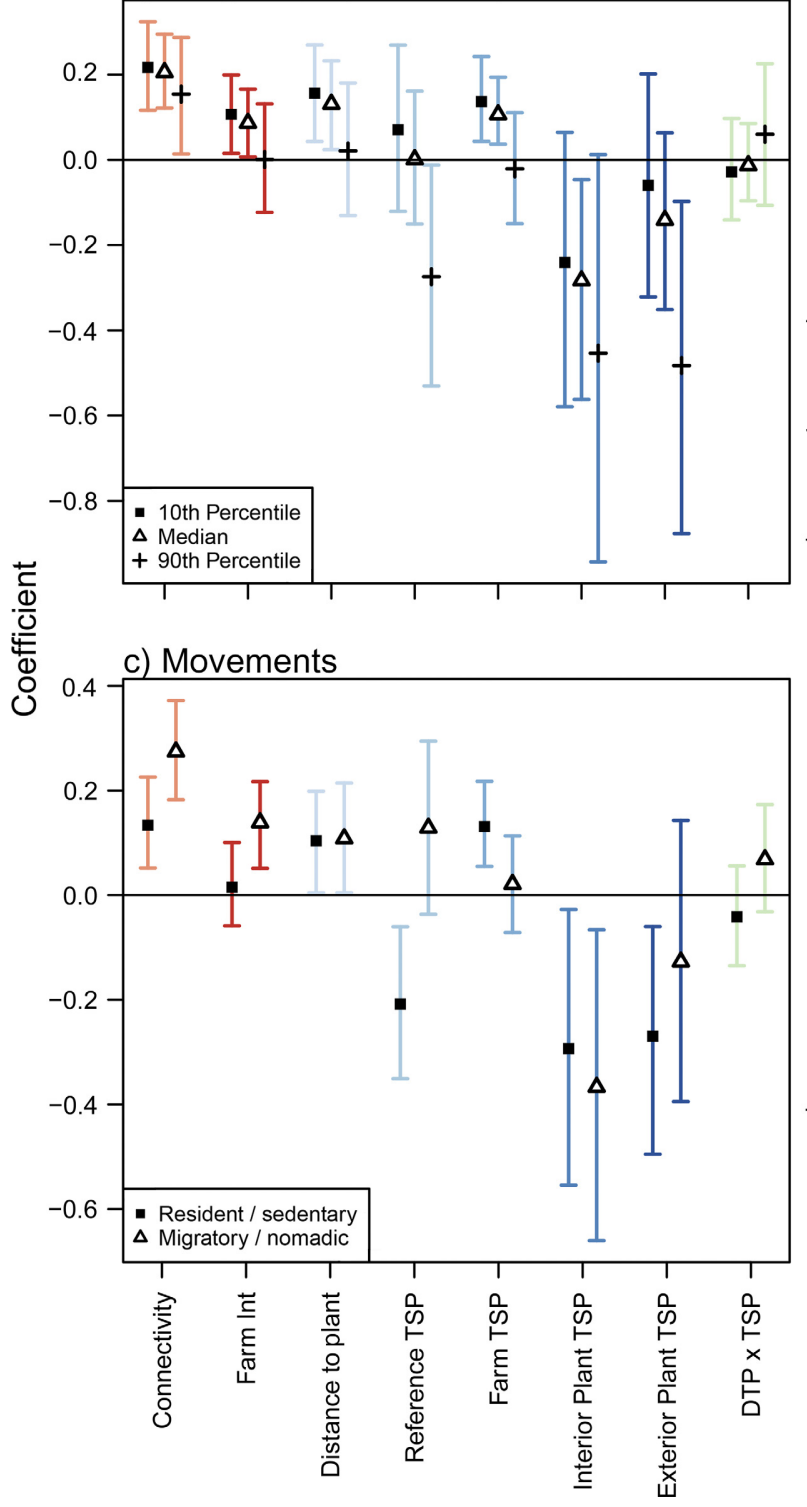

b) Dietary group

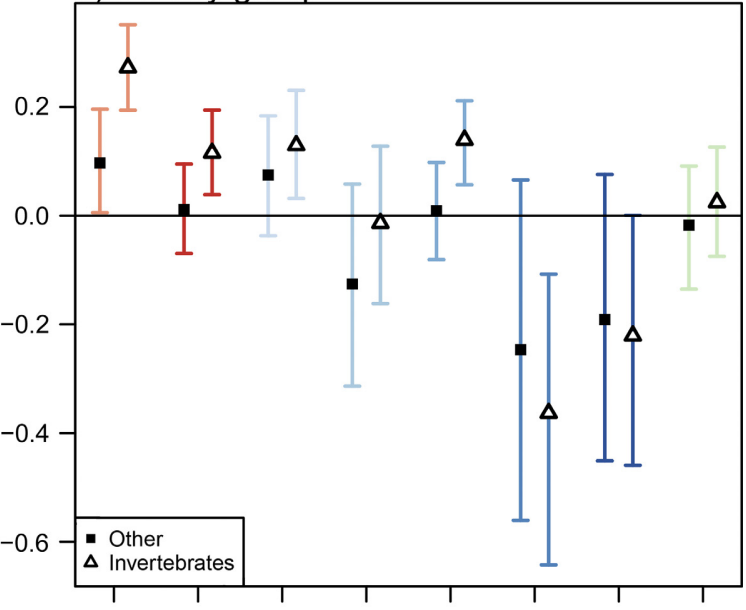

d) Main nest site

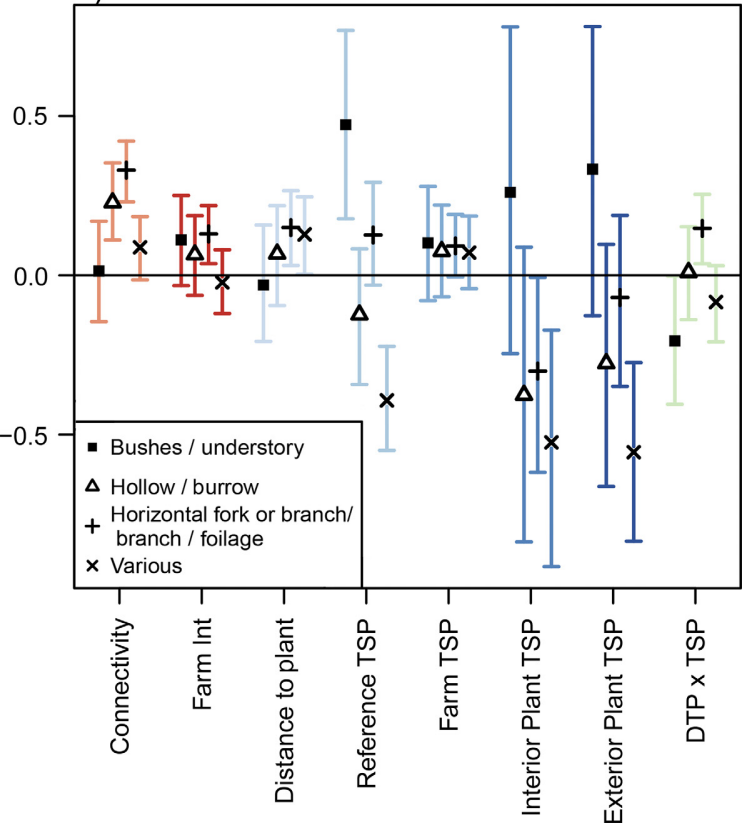

FIG. 3. Fourth-corner results for the model with additive effects of initial and subsequent landscape transformation. We modeled the effect of each of the following traits in four separate fourth corner models: (a) Body mass (cube root) was modeled as a continuous trait, but for purposes of illustration we chose to examine the median and the 10th and 90th percentiles of body mass. Posterior medians and 95\% credible intervals are plotted for each of the above-mentioned percentiles of body mass: (b) main food, (c) movements, (d) main nest site (see Appendix S4). We omitted the intercepts for each context for clarity of presentation. TSP, time since plantation establishment; DTP, distance to plantation; int, intercept.

the same period. Bird species richness remained largely unchanged in reference woodland patches surrounded by farmland and located distant from any plantation establishment.

\section{Discussion}

Human-modified landscapes worldwide are increasingly subject to repeated large-scale changes in land use (Watson et al. 2014). Despite the prevalence of such perturbations, the impacts on biodiversity of repeated, successive changes in land use remain poorly known. In particular, few studies have quantified the potential for additive or interactive relationships between previous transformation and more recent transformation. In addition, the temporal effects of the history of successive matrix change on biota associated with biological legacies have been poorly documented. These are critical knowledge gaps given the scale of such transformations worldwide, and the lack of regulatory controls 
surrounding the impacts of changes in human land use on biodiversity (compared with initial conversion of intact landscapes). We identified marked effects of plantation-generated transformation on individual bird species, either independent from, or interacting with, the effects of initial transformation. Indeed, the vast majority of the 57 birds species we modeled responded to recent exotic plantation establishment either independently from patterns of initial conversion (20 species), or more commonly in conjunction with effects of initial transformation, either interactively (18 species) or additively (15 species). Only one species responded solely to initial transformation variables (patch size and connectivity); but not subsequent transformation associated with plantation establishment (Fig. 2; Appendix S2: Table S2). We also found that plantation establishment generated new regional-level spatial processes shaping bird occurrence, with effects detected in woodland patches in farmland located well beyond the plantation boundary. Plantation-generated transformation also selected for species with different traits compared to the initial transformation, suggesting it is acting as a different filter on the bird community. Our findings have important consequences for biodiversity conservation in human-dominated landscapes.

\section{General findings}

We posed five competing hypotheses about how biodiversity responds to landscape transformation. We found varying support for the first four hypotheses. Only a few species' responses were consistent with Hypothesis 1 (no effects of either kind of transformation, three species) or Hypothesis 2 (effects of initial transformation with no impacts of subsequent [plantation-generated] transformation, one species). The majority of bird taxa exhibited responses either independent of the previous transformation (Hypothesis $3=20$ species) or to a combination of the two transformations in either additive or interactive ways (Hypothesis $4=33$ species). These results highlight the dominance of the most recent (plantationgenerated) transformation effects on contemporary patterns of species occurrence, although the prevalence of additive and interactive effects for more than half the taxa we modeled suggests that biological legacies remaining from previous land use also affect biota in patches.

Individual species responses were characterized by a prevalence of time since plantation establishment effects (Appendix S2: Table S2 and Appendix S3). Plantation establishment leads to marked changes in the structure of vegetation cover as well as large changes in microclimate. Such modifications to the matrix may alter connectivity and resource availability for a range of species with corresponding impacts on species occurrence (Driscoll et al. 2013). These changes associated with matrix conversion may disadvantage the use of remaining woodland patches by some species (e.g., open-country taxa; e.g., Common Starling, Willie Wagtail, and Whiteplumed Honeyeater) but benefit others (like those that are forest generalists; e.g., Common Blackbird, Golden Whistler and Yellow-faced Honeyeater). Notably, we found that such time since plantation establishment effects were often mediated by the effects of other covariates such as patch size and the number of edges, sometimes in complex interactive ways (Fig. 2; Appendix S2: Table S2 and Appendix S3). For instance, among the more complex patterns of response were interactions between time since plantation establishment effects and distance from the plantation to woodland patches. As an example, some bird species avoided farmland patches close to the plantation at the outset of our investigation, but such patterns were no longer evident 15 yr later. Disturbance associated with the initial phases of plantation establishment including bulldozing of roads and deepripping and mounding of soil to create a suitable substrate for planting Radiata Pine trees may have resulted in some species temporarily avoiding farmland areas close to the plantation (Appendix S2: Table S2 and Appendix S3). Plots of the distance to plantation effects for several bird species (Fig. 2; Appendix S3) revealed a marked difference between the response at 15-20 yr after plantation establishment vs. other time periods. Fifteen years is the approximate time of canopy closure and thinning in pine stands and this may, in part, explain some of the temporally dynamic effects we quantified.

We found that time since plantation establishment effects occurred not only in woodland patches located within the boundary of the plantation, but were also observed in the woodland patches on farms up to $6 \mathrm{~km}$ away from the plantation (as reflected by Distance to Plantation effects for a number of species). This suggests the influence of plantation establishment can extend over large distances (sometimes exceeding several kilometers) into adjacent environments that are not dominated by plantations. The reasons for this finding remain unclear. It is possible that our findings may be associated with the prevalence of native avian predators in the plantation-dominated landscape and corresponding impacts on nesting success (Okada et al. 2016). Notably, the adjacency effects we identified within adjacent farmland differ from classic edge effects, which quantify the effect of proximity to an edge between two land cover types (Ries et al. 2004). Work in tropical environments has shown that the effects of fires, logging, invasive species, and other kinds of disturbances that arise from within human-modified areas may have severe negative influences many kilometers into adjacent tropical forests, including otherwise intact reserves (Laurance 2000). These findings, together with the results from our empirical study, demonstrate the potential for landscape transformation to affect biodiversity at spatial scales far greater than the scale of land-use conversion. This has important implications because such adjacency effects are generally ignored in regulatory frameworks such as environmental impact assessments. 
Our results suggest that understanding the effects of new forms of land use change will often demand careful quantification of how species respond to the preceding form of landscape transformation, the most recent kind of transformation, as well as the conjoint impacts of both. Indeed, we suggest that a new approach to fragmentation studies may be warranted, one that incorporates quantification of multiple successive forms of landscape transformation, and other contextual factors. Moreover, the strongly time-dependent effects that we found illustrate that snapshot and matrix comparison studies, which currently dominate the literature on landscape transformation (see Lindenmayer and Fischer 2006, Collinge 2009), may provide inaccurate perspectives of the long-term effects of multiple successive transformation on biodiversity. This is because the trajectory of species occurrence may change as the matrix changes and interacts in complex ways with the biological legacies remaining from previous transformations (e.g., patches of remnant native vegetation) and hence snapshot studies may underestimate temporal patterns for some species and overestimate them for others. This is underscored by the many species for which complex models were developed such as those where the effects of landscape context and distance to the plantation changed over time and in response to various combinations of initial transformation variables (patch size and connectivity) and plantation variables (exterior vs. interior location; e.g., Eastern Rosella, Gang-Gang Cockatoo, White-throated Gerygone and White-plumed Honeyeater [see Appendix S3: Fig, S1]).

We have identified a set of processes that may guide future hypothesis testing about the effects of repeated landscape transformations. These include large-scale adjacency effects (where one matrix type influences biodiversity patterns of habitat patches embedded in an adjacent matrix type) and landscape context effects (immediate matrix type), and important interactions between spatial and temporal patterns of landscape change. Some of these complex and interacting effects have been mentioned in conceptual work on the importance of the matrix (Driscoll et al. 2013). However, to date, the effects of land conversion involving change from one large-scale matrix type to another over a long time frame have only rarely been documented (but see Law et al. 2014, 2017, Yanjiao et al. 2017).

\section{Life history analyses}

As part of testing Hypothesis 5 concerning whether initial and subsequent landscape transformation select for different bird life history traits (see Introduction), we sought to determine if species-specific responses to plantation-generated transformation could be predicted from life history attributes, as done in some studies of the effects of transformation of intact landscapes (Galetti et al. 2013). Theory such as the "performance filtering hypothesis" (Mouillot et al. 2012, Barnagaud et al.
2014) predicts that changes in landscape structure can select for different traits than those selected for prior to the most recent transformation. Consistent with this, we found compelling evidence of differences in life history responses to the different kinds of transformation. Plantation-generated transformation was therefore an additional filter selecting for species with different traits from those species that survived the first filter associated with the clearing of primary habitat.

Body size was one of the trait filters for which we found differences between farmland and plantation landscapes (Fig. 3). We found that large-bodied birds were those that declined fastest in the woodland patches located within the plantation. A possible explanation for this finding may be that large birds often dominate woodland environments in heavily cleared farmland (Lindenmayer et al. 2012) and they also have larger territories than small birds (Schoener 1968) meaning that plantation-dominated landscapes may be unsuitable for them. Nesting type was another life history attribute for which there were differences between initial and subsequent landscape transformation (Fig. 3). Shrub and understorey nesters became more prevalent over time in woodland patches close to the plantation. This change may be associated with the increase in the number and size of thickets of invasive blackberry (Rubus fruticosus) within and close to the radiata pine plantations in our study area over time (Lindenmayer et al. 2001). These are places where understorey and shrub-nesting bird species often chose to nest (Okada et al. 2016).

Despite many characteristics of the woodland patches remaining largely unaltered throughout our $18 \mathrm{yr}$ investigation, the matrix had a profound effect on the kinds of species inhabiting them, with such impacts often magnified over time as the matrix continued to change (in this case, the maturation of pine stands). These findings are consistent with predictions from the general conceptual model of the matrix developed by (Driscoll et al. 2013) in which the matrix can influence patchdependent species by affecting movement, resource availability and abiotic conditions. Indeed, the results of our life history analyses revealed changes in life history attributes such as movement capability, diet, body mass, and nesting type associated with the transformation from cleared pastures to pine plantations as well as between woodland remnants at the exterior vs. the interior of the plantation and in response to patch attributes like size and connectivity (Fig. 3).

\section{Species richness results}

The substantial effect of plantation-generated landscape transformation on the majority of species (53 of the 57 modeled taxa) was in stark contrast with its limited effects on species richness. This suggests that plantation-generated transformation leads to a change in species identities, rather than declines in the total number of species occurring within a site. Limited effects of 
this more recent form of transformation are different from the results of the numerous studies of primary habitat clearing where species richness is often significantly eroded by human modification (Rosenzweig 1995, Lindenmayer and Fischer 2006, Haddad et al. 2015).

\section{Implications for landscape management}

We have shown that new kinds of landscape transformation (such as tree plantation establishment on semi-cleared pastures) can radically alter the trajectory of species that have persisted for many decades in previously modified landscapes. This highlights the challenges but also opportunities for conserving taxa in ever changing human-dominated environments. Indeed, some species will benefit from new kinds of landscape transformation such as plantation establishment. These can include species of conservation concern; examples from our study included the Crested Shrike-tit, Eastern Yellow Robin, Gang-gang Cockatoo, and Jacky Winter. Several of these species increased in woodland remnants located in the plantation as the surrounding stands of radiata pine matured (Appendix S3: Fig. S1). Conversely, other species of conservation concern may be maladapted to the new conditions created by successive landscape transformation, even when key habitat features such as patches of endangered woodland are retained. Examples from our investigation were the Dusky Woodswallow and the Brown Treecreeper; the later species declined in patches surrounded by pine as the plantation matured, but increased over the same time period in patches that remained surrounded by farmland (Fig. 2e). Thus, repeated changes in large-scale land use represent an important challenge for conserving biodiversity in human-dominated landscapes and whilst benefiting some species, could produce a new cohort of species of conservation concern. A key management recommendation is that landscape managers should avoid comprehensive transformations that result in all parts of a formerly human-modified landscape being fully converted to a new kind of land use. That is, a diversity of forms of landscape cover will likely be needed to conserve the full range of species, including those that have adapted to the conditions created by previous forms of human land use.

We suggest that the impacts of repeated changes in land use will be, to some extent, landscape and transformation-type specific. However, some factors are likely to have an important influence on how species respond to successive transformations. The number, type, and spatial extent of biological legacies such as patches of remnant native vegetation will likely have an important effect on biodiversity. We therefore suggest that the retention of patches of remnant native vegetation cover will be critical for conserving biodiversity during landscape transformation and they should not be removed (such as during the process of plantation establishment). However, it should also be acknowledged that the conservation value of such areas will change over time because, as we have shown, the matrix surrounding these patches also will have a major impact on which species (Fig. 2; Appendix S3; and which functional groups of species; Fig. 3; Appendix S4) persist in these areas. Thus, a landscape which is currently able to support a certain suite of species in habitat remnants may no longer be able to support those species under a different dominant land use, even if remnant patches are unmodified.

The direction of landscape conversion is another factor that will affect the persistence of biodiversity in modified landscapes; while the same two filters are being applied, a transformation of the dominant land use from semi-cleared pasture to tree plantations may result in a very different biotic assemblage than a conversion from plantations to pasture (as is occurring in large parts of some nations such as Australia (Australian Broadcasting Corporation 2015). Watson et al. (2014) argued that the effects of repeated landscape transformation will be most substantial when large changes in vegetation and landscape structure occur.

Plantation expansion is occurring on all vegetated continents and is a major form of land use change globally, as an increasing proportion of the world's timber and paper is sourced from plantations (Bauhus et al. 2010, FAO 2010). While tree plantation establishment is occurring soon after the of clearing original forest cover in some jurisdictions (e.g., oil palm in tropical environments [Azhar et al. 2014], eucalypts and conifers in South America [Barlow et al. 2016, Fierro et al. 2017]), in many other cases, plantation establishment is a form of landscape transformation occurring in already extensively modified landscapes, where remnants of original vegetation cover remain (Brazil, South Africa, Australia; Bauhus et al. 2010, Hulvey et al. 2013). For example, government initiatives in many nations have subsidized the transformation of millions of hectares of agricultural land into tree plantations (Lindenmayer et al. 2015, Hua et al. 2016). Our study clearly shows that the effects of such transformations on biodiversity will likely be substantial, and may be very different from effects on biota when landscapes where first subject to human modification. On this basis, we suggest that new forms of land use change in already human-modified landscapes should be subject to careful regulatory controls and rigorous assessment of potential impacts, particularly on species of conservation concern.

\section{ACKNOWLEDGMENTS}

Work in the Nanangroe quasi-experiment has been funded through grants from the Rural Industries Research and Development Corporation, Land and Water Australia (now defunct), the Australian Research Council, and the Long-term Ecological Research Network (also now defunct, but formerly part of the Terrestrial Ecosystem Research Network). We thank the farmers from the Nanangroe district who allowed access to their land to survey birds. Claire Shepherd and Tabitha Boyer assisted in manuscript preparation. D. B. Lindenmayer designed 
and established the study and led the writing. W. Blanchard led the statistical analysis. M. Crane managed the field data collection program. All authors contributed to the conceptual development, analysis interpretation, and writing of the study.

\section{Literature Cited}

Australian Broadcasting Corporation. 2015. Farmers in northern NSW buy failed managed investment scheme forestry plantations. http://www.abc.net.au/news/rural/2015-09-28/ma naged-investment-schemes-plantation-sales-nsw/6810410

Azhar, B., D. B. Lindenmayer, J. Wood, J. Fischer, and M. Zakaria. 2014. Ecological impacts of oil palm agriculture on native mammal richness and feeding guilds in Peninsular Malaysia. Biodiversity and Conservation 23:11751191.

Barlow, J., et al. 2016. Anthropogenic disturbance in tropical forests can double biodiversity loss from deforestation. Nature 535:144-147.

Barnagaud, J.-V., L. Barbaro, J. Papaï, M. Deconchat, and E. G. Brockerhoff. 2014. Habitat filtering by landscape and local forest composition in native and exotic New Zealand birds. Ecology 95:78-87.

Basiron, Y. 2007. Palm oil production through sustainable plantations. European Journal of Lipid Science and Technology 109:289-295.

Bauhus, J., P. van der Meer, and M. Kanninen. 2010. Ecosystem goods and services from plantation forests. Earthscan, London, UK.

Buerkner, P.-C. 2017. brms: An R Package for Bayesian Multilevel Models Using Stan. Journal of Statistical Software 80:1-28.

Collinge, S. K. 2009. Ecology of fragmented landscapes. The John Hopkins University Press, Baltimore, Maryland, USA.

Cunningham, R., and D. B. Lindenmayer. 2016. Approaches to landscape scale inference and design issues. Current Landscape Ecology Reports 2:42-50.

Cunningham, R. B., D. B. Lindenmayer, M. Crane, D. R. Michael, P. S. Barton, P. Gibbons, S. Okada, K. Ikin, and J. A. R. Stein. 2014. The law of diminishing returns: woodland birds respond to native vegetation cover at multiple spatial scales and over time. Diversity and Distributions 20:59-71.

Driscoll, D. A., S. C. Banks, P. S. Barton, D. B. Lindenmayer, and A. L. Smith. 2013. Conceptual domain of the matrix in fragmented landscapes. Trends in Ecology \& Evolution 28:605-613.

FAO. 2010. Global forest resources assessment 2010: Main report. FAO, Rome, Italy.

Felton, A., E. J. Knight, J. T. Wood, C. Zammit, and D. B. Lindenmayer. 2010. A meta-analysis of fauna and flora species richness and abundance in plantations and pasture lands. Biological Conservation 143:545-554.

Fierro, A., A. A. Grez, P. M. Vergara, A. Ramírez-Hernández, and E. Micó. 2017. How does the replacement of native forest by exotic forest plantations affect the diversity, abundance and trophic structure of saproxylic beetle assemblages? Forest Ecology and Management 405:246-256.

Forman, R. T. T. 1995. Land Mosaics: the ecology of landscapes and regions. Cambridge University Press, New York, New York, USA.

Franklin, J. F., and J. A. MacMahon. 2000. Messages from a mountain. Science 288:1183-1185.

Frelich, L. E. 2005. Forest dynamics and disturbance regimes. Studies from temperate evergreen-deciduous forests. Cambridge University Press, Cambridge, UK.
Galetti, M., et al. 2013. Functional extinction of birds drives rapid evolutionary changes in seed size. Science 340:10861090.

Gelman, A., A. Jakulin, M. G. Pittau, and Y.-S. Su. 2008. A weakly informative default prior distribution for logistic and other regression models. Annals of Applied Statistics 2:1360 1383.

Gelman, A., J. Hwang, and A. Vehtari. 2014. Understanding predictive information criteria for Bayesian models. Statistics and Computing 24:997-1016.

Giam, X., G. R. Clements, S. A. Aziz, K. Y. Chong, and J. Miettinen. 2011. Rethinking the 'back to wilderness' concept for Sundaland's forests. Biological Conservation 144:31493152 .

Gibbons, P., and M. Boak. 2002. The value of paddock trees for regional conservation in an agricultural landscape. Ecological Management \& Restoration 3:205-210.

Haddad, N. M., et al. 2015. Habitat fragmentation and its lasting impact on Earth's ecosystems. Science Advances 1: e1500052.

Hua, F., X. Wang, X. Zheng, B. Fisher, L. Wang, J. Zhu, Y. Tang, D. W. Yu, and D. S. Wilcove. 2016. Opportunities for biodiversity gains under the world's largest reforestation programme. Nature Communications 7: Art. no. 12717.

Hui, F. K. C. 2016. BORAL - Bayesian Ordination and Regression Analysis of Multivariate Abundance Data in R. Methods in Ecology and Evolution 7:744-750.

Hulvey, K. B., R. J. Hobbs, R. J. Standish, D. B. Lindenmayer, L. Lach, and M. P. Perring. 2013. Benefits of tree mixes in carbon plantings. Nature Climate Change 3:869-874.

Hutto, R. 2016. Should scientists be required to use a modelbased solution to adjust for possible distance-based detectability bias? Ecological Applications 26:1287-1294.

Laurance, W. F. 2000. Do edge effects occur over large spatial scales? Trends in Ecology \& Evolution 15:134-135.

Law, B., M. Chidel, T. Brassil, G. Turner, and A. Kathuria. 2014. Trends in bird diversity over 12 years in response to large-scale eucalypt plantation establishment: implications for extensive carbon plantings. Forest Ecology and Management 322:58-68.

Law, B. S., M. Chidel, T. Brassil, G. Turner, and L. Gonsalves. 2017. Winners and losers among mammals and nocturnal birds over 17 years in response to large-scale eucalypt plantation establishment on farmland. Forest Ecology and Management 399:108-119.

Likens, G. E., editor. 1989. Long-term studies in ecology: approaches and alternatives. Springer-Verlag, New York, New York, USA.

Lindenmayer, D. B. 2009. Large-scale landscape experiments. Lessons from Tumut. Cambridge University Press, Cambridge, UK.

Lindenmayer, D. B., and J. Fischer. 2006. Habitat fragmentation and landscape change. Island Press, Washington, D.C., USA.

Lindenmayer, D. B., and J. F. Franklin. 2002. Conserving forest biodiversity: a comprehensive multiscaled approach. Island Press, Washington, D.C., USA.

Lindenmayer, D. B., R. B. Cunningham, C. MacGregor, C. Tribolet, and C. F. Donnelly. 2001. A prospective longitudinal study of landscape matrix effects on woodland remnants: experimental design and baseline data for mammals, reptiles and nocturnal birds. Biological Conservation 101:157-169.

Lindenmayer, D. B., R. B. Cunningham, C. McGregor, M. Crane, D. Michael, R. Montague-Drake, J. Fischer, A. Felton, and A. Manning. 2008. Temporal changes in vertebrates during landscape transformation: a large-scale "natural experiment.” Ecological Monographs 78:567-590. 
Lindenmayer, D. B., A. F. Bennett, and R. J. Hobbs, editors 2010. Temperate woodland conservation and management. CSIRO Publishing, Melbourne, Victoria, Australia.

Lindenmayer, D. B., A. R. Northrop-Mackie, R. MontagueDrake, D. Michael, M. Crane, S. Okada, C. MacGregor, and P. Gibbons. 2012. Not all kinds of regrowth are created equal. Regrowth type influences bird assemblages in threatened Australian woodland ecosystems. PLoS ONE 7:e34527.

Lindenmayer, D. B., C. Messier, A. Paquette, and R. J. Hobbs. 2015. Managing tree plantations as novel socio-ecological systems: Australian and North American perspectives. Canadian Journal of Forest Research 45:1426-1432.

Lindenmayer, D. B., P. W. Lane, P. S. Barton, M. Crane, K. Ikin, D. R. Michael, and S. Okada. 2016a. Long-term bird colonization and turnover in restored woodlands. Biodiversity and Conservation 25:1587-1603.

Lindenmayer, D. B., D. Michael, M. Crane, S. Okada, D. Florance, P. Barton, and K. Ikin. 2016b. Wildlife conservation in farm landscapes. CSIRO Publishing, Melbourne, Victoria, Australia.

Maxwell, S., R. A. Fuller, T. Brooks, and J. Watson. 2016. Biodiversity: The ravages of guns, nets and bulldozers. Nature 536:143-145.

Montague-Drake, R. M., D. B. Lindenmayer, and R. B. Cunningham. 2009. Factors affecting site occupancy by woodland bird species of conservation concern. Biological Conservation 142:2896-2903.

Mouillot, D., N. A. Graham, S. Villeger, N. W. Mason, and D. R. Bellwood. 2012. A functional approach reveals community responses to disturbances. Trends in Ecology \& Evolution 28:167-177.

Okada, S., D. B. Lindenmayer, J. T. Wood, M. J. Crane, and J. C. Pierson. 2016. How does a transforming landscape influence bird breeding success? Landscape Ecology 32:1039-1048.

R Core Team. 2015. R: a language and environment for statistical computing. R Foundation for Statistical Computing, Vienna, Austria. www.R-project.org

Ricketts, T. H. 2001. The matrix matters: effective isolation in fragmented landscapes. American Naturalist 158:87-99.
Ries, L., R. J. Fletcher, J. Battin, and T. D. Sisk. 2004. Ecological responses to habitat edges: Mechanisms, models, and variability explained. Annual Review of Ecology, Evolution, and Systematics 35:491-522.

Rosenzweig, M. L. 1995. Species diversity in space and time. Cambridge University Press, Cambridge, UK.

RStudio Team. 2015. RStudio: integrated development for R. RStudio Inc., Boston, Massachusetts, USA.

Runge, C., J. E. Watson, S. H. Butchart, J. O. Hanson, H. P. Possingham, and R. A. Fuller. 2015. Protected areas and global conservation of migratory birds. Science 350:1255-1258.

Schoener, T. W. 1968. Sizes of feeding territories among birds. Ecology 49:123-141.

Vehtari, A., A. Gelman and J. Gabry. 2015. Efficient implementation of leave-one-out cross-validation and WAIC for evaluating fitted Bayesian models. http://arxiv.org/abs/1507. 04544

Venter, O., et al. 2016. Sixteen years of change in the global terrestrial human footprint and implications for biodiversity conservation. Nature Communications 7:12558.

Watanabe, S. 2010. Asymptotic equivalence of Bayes cross validation and widely applicable information criterion in singular learning theory. Journal of Machine Learning Research 11:3571-3594.

Watson, S. J., G. W. Luck, P. G. Spooner, and D. M. Watson. 2014. Land-use change: incorporating the frequency, sequence, time span, and magnitude of changes into ecological research. Frontiers in Ecology and the Environment 12:241-249.

Welsh, A. H., D. B. Lindenmayer, and C. F. Donnelly. 2013. Fitting and interpreting occupancy models. PLoS ONE 8: e52015.

Welsh, A. H., D. B. Lindenmayer, and C. F. Donnelly. 2015. Adjusting for one issue while ignoring others can make things worse. PLoS ONE 10:e120817.

Yanjiao, R., Y. Lü, Y. F. Bojie, and K. Zhang. 2017. Biodiversity and ecosystem functional enhancement by forest restoration: A meta-analysis in China. Land Degradation and Development 28:2062-2073.

\section{SUPPORTING INFORMATION}

Additional supporting information may be found online at: http://onlinelibrary.wiley.com/doi/10.1002/ecm.1362/full

Data Availability

Data from this study are available from the Dryad Digital Repository: https://doi.org/10.5061/dryad.ct677k9 